\title{
SOME GENERALIZED NONLINEAR GAMIDOV TYPE INTEGRAL INEQUALITIES WITH MAXIMA IN TWO VARIABLES AND THEIR WEAKLY SINGULAR ANALOGUES
}

\author{
RUn XU AND XiAngting MA
}

\begin{abstract}
In this paper, some new nonlinear Gronwall-Bellman-Gamidov type integral inequalities with maxima in two variables and their weakly singular analogues are discussed. By using analysis techniques, such as change of variable, amplification method, differential and integration, inverse function, we estimated the upper bounds of the unknown functions. For illustrating the validity of the inequalities established, some examples are given to study the boundedness and uniqueness of solutions of a certain Gamidov type weakly singular integral equations.
\end{abstract}

Mathematics subject classification (2010): 42B20, 26D07, 26D15.

Keywords and phrases: Gamidov type, integral inequality, integral equations, maxima, weakly singu-

lar.

\section{REFERENCES}

[1] T.H. GRONwalL, Note on the derivatives with respect to a parameter of the solutions of a system of differential equations, Annals of Mathematics, vol. 20, no. 4, pp. 292-296, 1919.

[2] R. Bellman, The stability of solutions of linear differential equations, Duke Mathematical Journal, vol. 10, pp. 643-647, 1943.

[3] I. BIHARI, A generalization of a lemma of Bellman and its application to uniqueness problems of differential equations, Acta Mathematica Academia Scientical Hungar, vol. 7, pp. 81-94, 1956.

[4] S.G. GAmidov, Certain integral inequalities for boundary value problems of differential equations, Differential Equations, vol. 5, pp. 463-472, 1969.

[5] D. Banov And P. Simeonov, Integral Inequalities and Applications, vol. 57 of Mathematics and Its Applications, Kluwer Academic Publishers, Dordrecht, The Netherlands, 1992.

[6] B.G. PAChPATTE, Inequalities for differential and integral equations, vol. 197 of Mathematics in Science and Engineering, Academic Press, San Diego, Calif, USA, 1998.

[7] R. P. AgarwaL, S. Deng AND W. ZHANG, Generalization of a retarded Gronwall-like inequality and its applications, Applied Mathematics and Computation, vol. 165, no. 3, pp. 599-612, 2005.

[8] W. S. WANG, A generalized retarded Gronwall-like inequality in two variables and applications to BVP, Applied Mathematics and Computation, vol. 191, no. 1, pp.144-154, 2007.

[9] Q. H. MA AND E. H. YANG, Estimates on solutions of some weakly singular Volterra integral inequalities, Acta Mathematical Application Sinica, vol. 25, no. 3, pp. 505-515, 2002.

[10] Q. H. MA AND J. PEČARIĆ, Some new explicit bounds for weakly singular integral inequalities with applications to fractional differential and integral equations, Journal of Mathematical Analysis and Applications, vol. 341, pp. 894-905, 2008.

[11] W. S. Cheung, Q. H. MA AND S. TSENG, Some new nonlinear weakly singular integral inequalities of Wendroff type with applications, Journal of Inequalities and Applications, vol. 2008, Article ID 909156, 13 pages, 2008.

[12] Run Xu, Fanwei Meng, Some New Weakly Singular Integral Inequalities and Their Applications to Fractional Differential Equations, Journal of Inequalities and Applications, (2016) 2016:78, 1-16.

[13] F. LAKHAL, A new nonlinear integral inequality of Wendroff type with continuous and weakly singular kernel and its application, Journal of Mathematical Inequalities, vol. 6, no. 3, pp. 367-379, 2012. 
[14] K. L. ZHENG, Bounds on some new weakly singular Wendroff-type integral inequalities and applications, Journal of Inequalities and Applications, vol. 2013, no. 1, 11 pages, 2013.

[15] K. L. Cheng, C. X. Guo And M. TAng, Some nonlinear Gronwall-Bellman-Gamidov integral inequalities and their weakly singular analogues with applications, Abstract and Applied Analysis, vol. 2014, Article ID 562691, 9 pages, 2014.

[16] K. L. CHENG AND C. X. Guo, New explicit bounds on Gamidov type integral inequalities for functions in two variables and their applications, Abstract and Applied Analysis, vol. 2014, Article ID 539701, 9 pages, 2014.

[17] B. ZHENG, Explicit bounds derived by some new inequalities and applications in fractional integral equations, Journal of Inequalities and Applications, vol. 4, no. 1, 12 pages, 2014.

[18] Q. H. MA AND J. PEČARIĆ, Estimates on solutions of some new nonlinear retarded VolterraFredholm type integral inequalities, Nonlinear Analysis, vol. 69, pp. 393-407, 2008.

[19] L. M. ZHAO, S. H. WU AND W. S. WANG, A generalized nonlinear Volterra-Fredholm type integral inequality and its application, Journal of Applied Mathematics, vol. 2014, Article ID 865136, 13 pages, 2014.

[20] Y. G. HuAng, W. S. WAng And Y. HuAng, A class of Volterra-Fredholm type weakly singular difference inequalities with power functions and their applications, Journal of Applied Mathematics, vol. 2014, Article ID 826173, 9 pages, 2014.

[21] A. Golev, S. Hristova And A. RAhnev, An algorithm for approximate solving of differential equations with maxima, Computational Mathematic and Application, vol. 60, pp. 2771-2778, 2010.

[22] S. G. Hristova And K. V. Stefanova, Some integral inequalities with maximum of the unknown functions, Advances in Dynamical Systems and Applications, vol. 6, no. 1, pp. 57-69, 2011.

[23] Y. YAN, A generalized nonlinear Gronwall-Bellman inequality with maxima in two variables, Journal of Applied Mathematics, vol. 2013, Article ID 853476, 10 pages, 2013.

[24] Y. YAN, On some new weakly singular Volterra integral inequalities with maxima and their applications, Journal of Inequalities and Applications, vol. 369, 16 pages, 2015.

[25] FAngCUi JiAng AND FAnWEI MENG, Explicit bounds on some new nonlinear integral inequalities with delay, Journal of Computational and Applied Mathematics, vol. 205, no. 1, pp. 479-486, 2007.

[26] Fanwei Meng, Jing Shao, Some new Volterra-Fredholm type dynamic integral inequalities on time scales, Applied Mathematics and Computation, 2013, 223(3): 444-451.

[27] Run Xu, Fanwei Meng, Cuinua Song, On Some Integral Inequalities on Time Scales and Their Applications, Journal of Inequalities and Applications, Volume 2010, Article ID 464976, 1-13.

[28] Tonglin WAng, Run XU, Some integral inequalities in two independent variables on time scales, Journal of Mathematical Inequalities, 2012, 6(1), 107-118.

[29] Tonglin Wang, Run Xu, Bounds for Some New Integral Inequalities With Delay on Time Scales, Journal of Mathematical Inequalities, 2012, 6(3), 355-366. 2012.09.

[30] Liwei Du, Run Xu, Some New Pachpatte Type Inequalities on Time Scales and their applications, Journal of Mathematical Inequalities, 2012, 6(2), 229-240. 2012.06.

[31] Run XU, Ying ZHANG, Generalized Gronwall fractional summation inequalities and their applications, Journal of Inequalities and Applications, (2015) 2015:242.

[32] Lingling Wan, Run Xu, Some generalized integral inequalities and there applications, Journal of Mathematical Inequalities, Vol 7, Number 3 (2013).

[33] Run Xu And Xiangting Ma, Some new retarded nonlinear Volterra-Fredholm type integral inequalities with maxima in two variables and their applications, Journal of Inequalities and Applications, (2017) 2017:187.

[34] Run Xu, Some New Nonlinear Weakly Singular Integral Inequalities and Their Applications, Journal of Mathematical Inequalities, Volume 11, Number 4 (2017), 1007-1018.

[35] Haidong Liu, FAnwei Meng, Some new generalized Volterra-Fredholm type discrete fractional sum inequalities and their applications, Journal of Inequalities and Applications (2016) 2016:213.

[36] Haidong LiU, FAnwei MENG, Some new nonlinear integral inequalities with weakly singular kernel and their applications to FDEs, Journal of Inequalities and Applications, 2015, (2015): 209.

[37] Haidong Liu, Some new integral inequalities with mixed nonlinearities for discontinuous functions, Advances in Difference Equations (2018), 2018: 22.

[38] HaIdong LiU, A class of retarded Volterra-Fredholm type integral inequalities on time scales and their applications, Journal of Inequalities and Applications (2017) 2017:293. 
[39] Haidong LiU, FAnwei Meng, Nonlinear retarded integral inequalities on time scales and their applications, Journal of Mathematical Inequalities. 12 (1) (2018) 219-234. 